\title{
Experimental Study of Gas-Liquid Flow Through Vertical Curves: A Parallel with Gas Locking Phenomenon in Centrifugal Pumps
}

\author{
Renan Marçal' ${ }^{1}$ Valdir Estevam ${ }^{1}$, Marcelo Souza de Castro ${ }^{1}$ \\ ${ }^{1}$ School of Mechanical Engineering - University of Campinas Mendeleyev 200, Campinas, Brazil \\ r228280@dac.unicamp.br; valdir_e@hotmail.com, mcastro@fem.unicamp.br
}

\section{Extended Abstract}

Centrifugal pumps are used in many industrial applications such as refrigeration systems, nuclear industry, food and oil production. The presence of free gas inside the pump, in a multi-phase flow, is common in several applications. At this point, phenomena such as surging and gas-locking are observed as the volumetric fraction of free gas increases [1]. The gaslocking phenomenon occurs when the pressure peak is not sufficient to overcome the hydrostatic pressure present in the pipe [2]. The gas-locking phenomenon is poorly studied in the literature by the difficulty in conducting experimental observations, this occurs by the formation of a large stationary bubble in the pump rotor, causing major system degradation and drastic reduction of pumping capacity. Due to the difficulty in analysing such flow characteristics in a complex geometry such as the rotor of a pump, this work proposes the study of it by analysing the gas-liquid two-phase flow in a curved duct, thus simulating the centrifugal field. In addition to, it is possible to study the transition from upward to downward flow, the formation of the stationary bubble and the liquid film, among other parameters. The experimental bench used possesses a curved duct (radius of $1,75 \mathrm{~m}$ ) of square section $(40 \times 40 \mathrm{~mm}$ ) made of acrylic with $1,96 \mathrm{~m}$ of total length, pressure measurements and temperature were made along the section. The input section is straight with $780 \mathrm{~mm}$ long. A total of 400 experiments of two-phase water-air and oil-air flows were performed at ambient temperature. Water and oil have a density of $998 \mathrm{~kg} / \mathrm{m}^{3}$ and $860 \mathrm{~kg} / \mathrm{m}^{3}$ and a viscosity of $1 \mathrm{cP}$ and $20 \mathrm{cP}$, respectively. In water-air experiments the water flow ranged from $500 \mathrm{~kg} / \mathrm{h}$ to $2000 \mathrm{~kg} / \mathrm{h}$ and from $0.09 \mathrm{~kg} / \mathrm{h}$ to $1 \mathrm{~kg} / \mathrm{h}$, in oil-air experiments the oil flow ranged from $200 \mathrm{~kg} / \mathrm{h}$ to 2600 $\mathrm{kg} / \mathrm{h}$ and gas between $0.07 \mathrm{~kg} / \mathrm{h}$ to $5 \mathrm{~kg} / \mathrm{h}$. In addition to filming with high resolution camera, made to identify the entry flow pattern, the formation and the characteristics of the elongated bubble, as well as the process of bubble release and recirculation in the final bubble region and characteristics of the liquid film. The flow patterns observed at the entrance were bubbles, dispersed bubbles and pistons. The elongated bubble was formed in medium liquid and low gas flows in the waterto-air flow and low liquid and gas flows in the oil- to-air flow. In the flows with oil there is the formation of small bubbles over the whole film, not observed in the water. As a result, in the flows with both fluids are observed disturbances in the interface (ripples), phenomena related to descending film hydrodynamic stability which may be related to the gas-locking phenomenon. Such results will serve as a basis for analysis of the gas-locking phenomena.

\section{References}

[1] V. Estevam, “A Phenomenological Analysis about centrifugal pump in two-phase flow operation,” Ph.D. dissertation, Dept. Mec. Eng., State University of Campinas, Campinas, SP.

[2] E. J. Dottore., "How to Prevent Gas Lock in Sucker Rod Pumps," Paper SPE 27010, Proceedings of SPE Latin America/Caribbean Petroleum Engineering Conference, Buenos Aires, Argentina, 1994.

[3] W. M. Verde, J. L. Biazussi, N. A. Sassim, A. C. Bannwart, "Experimental study of gas-liquid two-phase flow patterns within centrifugal pumps impellers," Exp. Therm. Fluid Sci., vol. 85, pp.37-51, 2017. 